調査·資料

\title{
GC-MS/MS によるダイエット健康食品中の医薬品成分分析法の検討
}

(平成 23 年 4 月 15 日受理)

\author{
山本新也*,1,3 墨 岡 成治 ${ }^{1}$ 藤 岡 正 信 $^{1}$ 三上栄一 ${ }^{2}$ 宮本謙一 ${ }^{3}$
}

A Study on Detection of Drugs in Slimming Health Foods Using GC-MS/MS

Shinya Yамамото*, 1,3 , Shigeharu Sumioka ${ }^{1}$, Masanobu FujiokA ${ }^{1}$, Eiichi Miкамi ${ }^{2}$ and Ken-ichi Miу амото ${ }^{3}$

${ }^{1}$ Toyohashi City Public Health Center (Institute of Public Health): 100 Nakahara, Nakano-cho, Toyohashi 441-8539, Japan;

${ }^{2}$ Aichi Prefectural Institute of Public Health:

7-6 Nagare, Tsuji-machi, Kita-ku, Nagoya 462-8576, Japan;

${ }^{3}$ Department of Medicinal Informatics, Graduate School of Medicine, Kanazawa University: 13-1 Takara-machi, Kanazawa 920-8641, Japan;

* Corresponding author

The determination of five drugs, fenfluramine (FEN), $N$-nitrosofenfluramine (NFE), sibutramine (SIB), mazindol (MAZ) and phenolphthalein (PHP), was studied in slimming health foods using GC-MS/MS. These drugs have been detected at high rates, especially in slimming health foods. Prolonged or excessive consumption of non-approved or unauthorized pharmaceuticals may cause serious adverse health consequences. In this study, samples were extracted with methanol and ultrasonication. Analyses were performed by GC-MS/MS, using established MS/ MS parameters in the electron ionization (EI) mode and chemical ionization (CI) mode. In the EI mode, the recoveries of five drugs from several types of slimming health foods such as tablets, capsules and tea-bags spiked at $1 \mu \mathrm{g} / \mathrm{mg}$ (except PHP, spiked at $4 \mu \mathrm{g} / \mathrm{mg}$ ) were in the range of $85.0-110.7 \%$ and $100 \mu \mathrm{g} / \mathrm{mg}$ (except PHP, spiked at $200 \mu \mathrm{g} / \mathrm{mg}$ ) were $94.9-102.9 \%$, respectively. In the CI mode, good recoveries of $80.3-102.2 \%$ (spiked at low concentration) and $92.8-103.2 \%$ (spiked at high concentration) were also obtained. We evaluated the present method using four slimming health foods, in which drugs had previously been detected. The results were similar to the previous results. These findings indicate that the present procedure for evaluating five drugs in slimming health foods by means of GC-MS/MS is useful.

(Received April 15, 2011)

Key words: ダイエット健康食品 slimming health food; 無承認無許可医薬品 non-approved or unauthorized pharmaceuticals; ガスクロマトグラフィー/タンデム質量分析法 GC-MS/MS; 電子イ オン化法 electron ionization mode; 化学イオン化法 chemical ionization mode

\section{緒言}

近年，健康食品における補完代替医療の考え方が普及 し，多くの健康食品が流通するようになってきた。しか し, これら健康食品の中には, 効果を高めるため本来医薬 品に該当する成分を製品の中に混入させ，薬事法違反（無 承認無許可医薬品）であるにもかかわらず健康食品として

* 連絡先：E-mail: yamamoto-shinya@city.toyohashi.lg.jp

1 豊橋市保健所 (衛生試験所)：７441-8539 愛知県豊橋市中 野町字中原 100

2 愛知県衛生研究所： $\mathbf{1} 462-8576$ 名古屋市北区辻町字流 7-6

3 金沢大学大学院医学系研究科： =920-8641 石川県金沢市宝 町 13-1
製造，輸入，販売されている例が少なくない1) 5). 医薬品 成分が添加された健康食品は，消費者の健康に予期せ女影 響を及ぼす危険があり $\left.{ }^{6)}, 7\right)$ ，健康被害が報告された場合， 衛生行政機関は迅速かつ正確に原因物質の特定を行う必要 がある*1. 現在, 健康食品中の医薬品成分の同定, 確認手 法として, 質量に関する情報が得られるLC-MS や GC-MS が汎用される*2. 一方 MS/MS は，MS の選択性

*1 厚生労働省医薬局長通知 “健康食品·無承認無許可医薬品健 康被害防止対応要領について”平成 14 年 10 月 4 日，医薬 発第 1004001 号

*2 厚生労働省医薬局監視指導·麻薬対策課長通知 “いわゆる健 康食品之称する無承認無許可医薬品の監視指導について”平 成 14 年 7 月 29 日, 医薬監麻発第 0729009 号 
が高められ, 複雑な組成成分中の微量成分の定性, 定量に

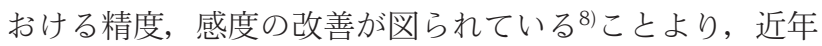
急速に普及してきている装置である。 GC-MS/MS は, GC-MS と比較して高選択性かつ定性能力も高( (9), 10)ため, 複雑な原料からなる食品中の成分分析に向いていると考え た。著者らは，健康被害事例に迅速加正確に対応するた め，これまでにダイエット健康食品中で検出された経緯の ある111,12)フェンフルラミン (FEN), $N$-ニトロソフェンフル ラミン (NFE), シブトラミン (SIB), マジンドール (MAZ)，打よびフェノールフタレイン (PHP)の 5 成分に ついて, 電子イオン化 (EI) 法と化学イオン化 (CI) 法の 2 種のイオン化法を使用した GC-MS/MS 一斉分析法を検討 したので報告する。

\section{実験方法}

\section{1. 試料}

過去に医薬品成分が検出された市販健康食品 4 検体
（カプセル型 3 検体，ティーバッグ型 1 検体）之愛知県内 で平成 20 年 11 月に購入した 10 検体（錠型 5 検体，力 プセル型 2 検体，ティーバッグ型 3 検体）を用いた.

\section{2. 試薬}

標準品：FEN 塩酸塩, NFE, PHP は和光純薬工業(株) 製，SIB 塩酸塩は LKT Laboratories 社製，MAZ はシグ マアルドリッチ社製を用いた。これらの構造を Fig. 1 に 示す.

メタノール：和光純薬工業(株)製メタノール 5000 を用 いた。

標準溶液：FEN 標準溶液と SIB 標準溶液は含塩酸塩と して，NFE 標準溶液，MAZ 標準溶液，PHP 標準溶液は 各標準品を秤量後, メ夕ノールで標準原液 $(1 \mathrm{mg} / \mathrm{mL})$ を 調製した。各標準原液の一定量を採り混合した後，メ夕 ノールで希釈し，検量線作成用溶液を調製した。添加用標 準溶液は, $50 \mathrm{mg} / \mathrm{mL}$ の標準原液をメ夕ノールで希釈し 添加した.<smiles>CCN(O)C(C)Cc1cccc(C(F)(F)F)c1</smiles>

$N$-Nitrosofenfluramine (NFE) (M.W. 260.3)<smiles>CNC(CC(C)C)C1(c2ccc(Cl)cc2)CCC1</smiles>

Sibutramine (SIB) (M.W. 279.9)

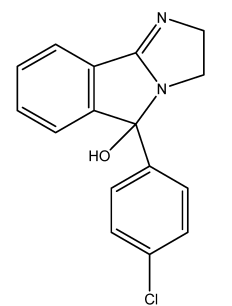

Mazindol (MAZ) (M.W. 284.7)<smiles>O=C1OC(c2ccc(O)cc2)(c2ccc(O)cc2)c2ccccc21</smiles>

Phenolphthalein (PHP)

(M.W. 318.3)

Fig. 1. Chemical structures of drugs in this study.

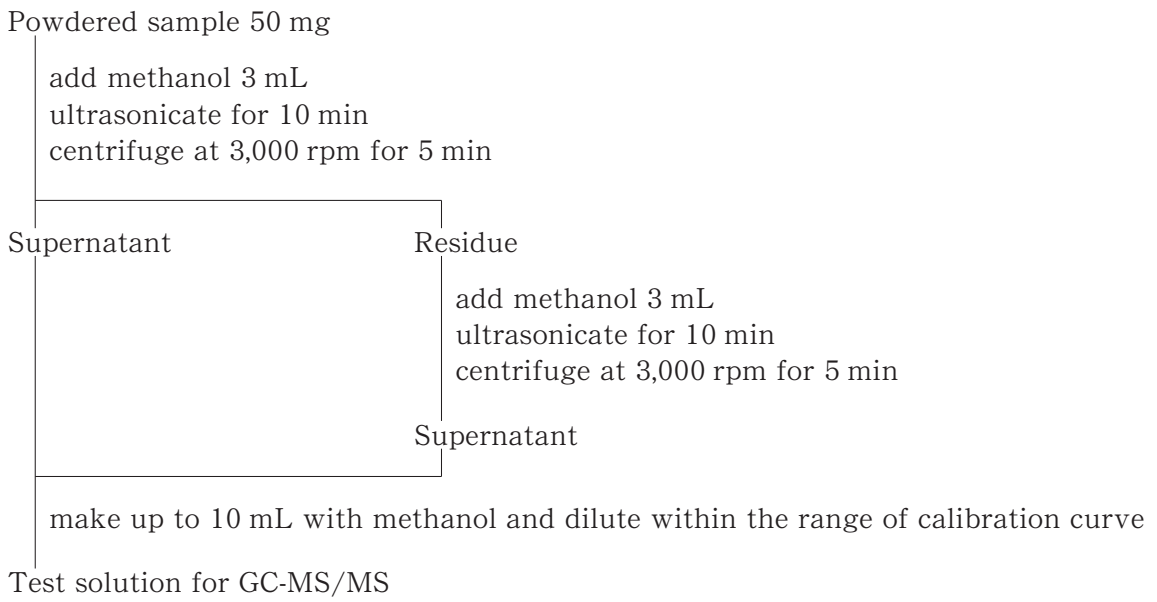

Scheme 1. Analytical procedure for non-approved or unauthorized pharmaceuticals. 
Table 1. Monitor ions and collision energies for GC-MS/MS

\begin{tabular}{|c|c|c|c|c|c|c|c|c|}
\hline \multirow{3}{*}{ Drug } & \multicolumn{6}{|c|}{ Monitor ion $(m / z)$} & \multirow{2}{*}{\multicolumn{2}{|c|}{ Collision energy $(\mathrm{V})$}} \\
\hline & \multicolumn{2}{|c|}{ Precursor } & \multicolumn{2}{|c|}{ Quantitation } & \multicolumn{2}{|c|}{ Qualifier } & & \\
\hline & EI & $\mathrm{CI}$ & EI & $\mathrm{CI}$ & EI & CI & EI & $\mathrm{CI}$ \\
\hline FEN & 159 & 212 (Positive) & 109 & 127 & 83 & 169 & 20 & 10 \\
\hline NFE & 186 & 159 (Negative) & 116 & 99 & 91 & 119 & 20 & 25 \\
\hline SIB & 114 & 114 (Positive) & 72 & 72 & 98 & 58 & 5 & 10 \\
\hline MAZ & 266 & 267 (Positive) & 204 & 204 & 238 & 231 & 20 & 25 \\
\hline PHP & 274 & 318 (Negative) & 181 & 180 & 257 & 273 & 15 & 25 \\
\hline
\end{tabular}

Electron energy: $70 \mathrm{eV}(\mathrm{EI}), 150 \mathrm{eV}(\mathrm{CI})$
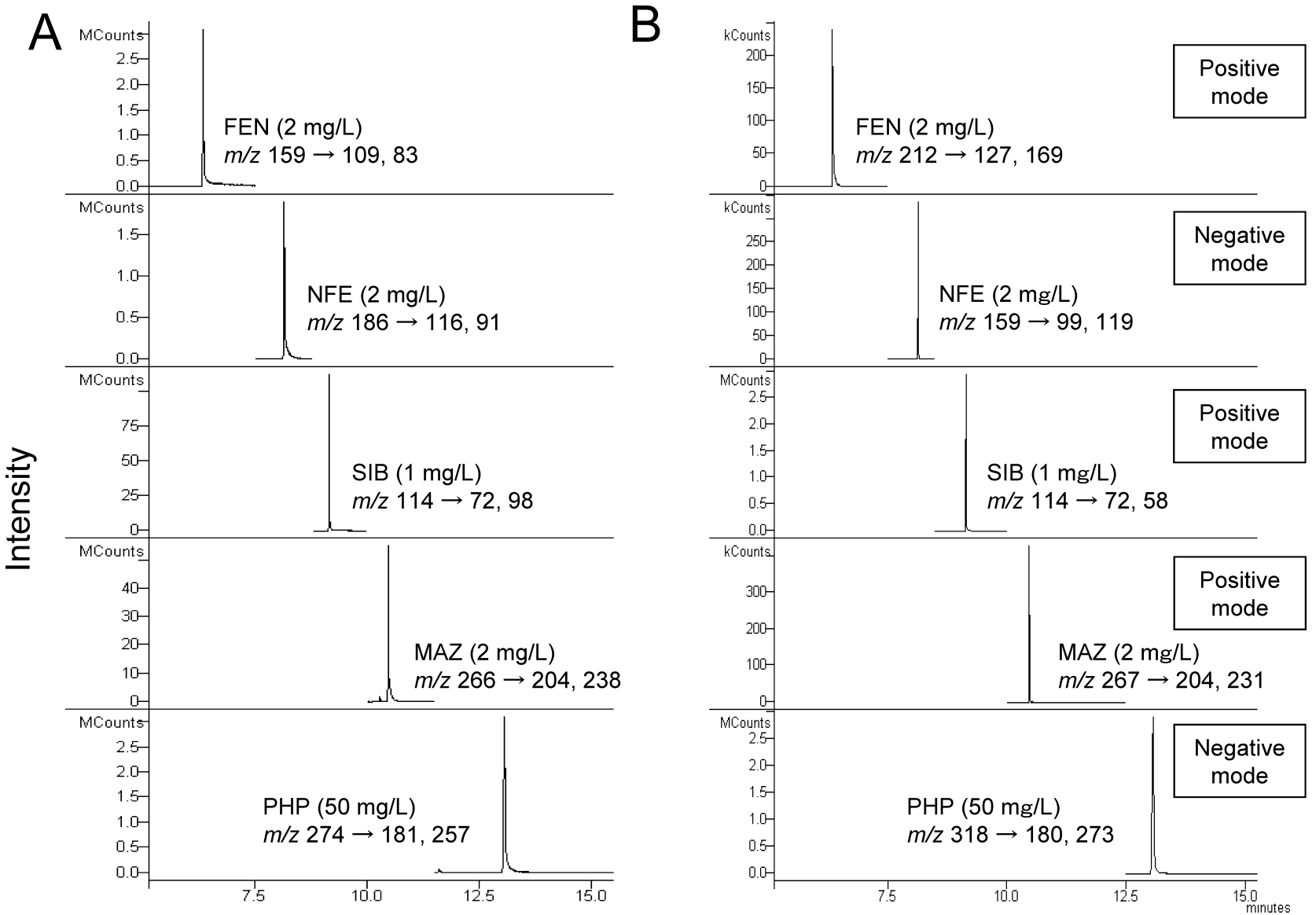

\section{Retention time}

Fig. 2. Typical GC-MS/MS chromatograms of drugs

A: EI mode chromatograms of standard solution. B: CI mode chromatograms of standard solution.

Table 2. Detection limits of drugs in slimming health foods

\begin{tabular}{|c|c|c|c|c|c|c|}
\hline \multirow{3}{*}{ Drug } & \multicolumn{6}{|c|}{ Limit of detection (LOD, $\mu \mathrm{g} / \mathrm{mg}, S / N=3$ ) } \\
\hline & \multicolumn{2}{|c|}{ Tablet } & \multicolumn{2}{|c|}{ Capsule } & \multicolumn{2}{|c|}{ Tea-bag } \\
\hline & EI & $\mathrm{CI}$ & EI & $\mathrm{CI}$ & EI & $\mathrm{CI}$ \\
\hline FEN & 0.005 & 0.001 & 0.005 & 0.0004 & 0.004 & 0.0005 \\
\hline NFE & 0.03 & 0.002 & 0.02 & 0.002 & 0.03 & 0.001 \\
\hline SIB & 0.001 & 0.0001 & 0.001 & 0.00004 & 0.0004 & 0.00004 \\
\hline MAZ & 0.002 & 0.0005 & 0.002 & 0.001 & 0.002 & 0.0004 \\
\hline PHP & 0.03 & 0.00005 & 0.02 & 0.00006 & 0.06 & 0.00004 \\
\hline
\end{tabular}




\section{3. 装}

粉砕機：TESCOM 社製ミル\&ミキサー，TML160を 用いた。

超音波洗浄機：シャープマニファクチャリングシステム (株)製，UT-205HS を用いた。

遠心分離機：Kubota 社製 8400 を用いた。

GC-MS / MS: Varian 社製 1200 シリーズ GC-MS / MS システム (1200 Quadrupole MS/MS, CP-3800 Gas Chromatograph, CP-8400 Autosampler) を用いた.

\section{GC-MS/MS 測定条件}

カラム：Varian 社製キャピラリーカラム VF-5MS + 5 $\mathrm{m}$ EZ-Guard (30 m ×0.25 mm i.d., 膜厚 $0.25 \mu \mathrm{m}$, ガー ドカラム $5 \mathrm{~m}$ ), カラム温度： $50^{\circ} \mathrm{C}$ で 2 分間保持した後, $20^{\circ} \mathrm{C} / \min$ で $170^{\circ} \mathrm{C}$ まで昇温し, 直ちに $50^{\circ} \mathrm{C} / \min$ で $320^{\circ} \mathrm{C}$ まで昇温, 5 分間保持, 注入口温度： $260^{\circ} \mathrm{C}$, 卜ラ ンスファーライン温度： $280^{\circ} \mathrm{C}$, イオンソース温度： $220^{\circ} \mathrm{C}$ ，キャリヤーガス：ヘリウム（流量 $1.5 \mathrm{~mL} / \mathrm{min}$ ), コリジョンガス：アルゴン, 注入量： $2 \mu \mathrm{L}$ （スプリット レス注入), CI ガス：メタン

\section{5. 試験溶液の調製}

試験溶液の調製法を Scheme 1 に示す。錠型のものは 粉砕機にて粉末とし，カプセル型およびティーバッグ型の ものは内容物を取り出した後粉末とし，それらの $50 \mathrm{mg}$ を秤取，10 mL 遠沈管に移した後メ夕ノール $3 \mathrm{~mL}$ を加 えた。その液を 10 分間超音波抽出した後，遠心分離 （3,000 回転で 5 分間）を行った。 上清を採り，残渣にメ タノール $3 \mathrm{~mL}$ を加え，同様の操作を行った。 上清を合わ せ,メタノールにて正確に $10 \mathrm{~mL}$ としたものを試験溶液 とした。

\section{6. 定量}

検量線作成用溶液を GC-MS/MS に注入し，3 回繰り返 し測定することによって得られたクロマトグラムのピーク 面積之標準成分量から EI, CI の各イオン化法ごとに検量 線を作成した。試験溶液は適宜希釈し，検量線法により各 医薬品成分濃度を求めた。

\section{結果および考察}

\section{MS/MS 測定条件の検討}

三上ら ${ }^{13)}$ は，EI と CI の両法を用いて GC-MS にて中国

Table 3. Recoveries of drugs from several types of slimming health foods using GC-MS/MS

\begin{tabular}{|c|c|c|c|c|c|c|c|c|}
\hline \multirow{3}{*}{ Drug } & \multirow{3}{*}{$\begin{array}{c}\text { Initial single } \\
\text { dosage } \\
(\mathrm{mg})\end{array}$} & \multirow{3}{*}{$\begin{array}{c}\text { Spiked } \\
\text { level } \\
(\mu \mathrm{g} / \mathrm{mg})\end{array}$} & \multicolumn{6}{|c|}{ Recovery (\%) } \\
\hline & & & \multicolumn{2}{|c|}{ Tablet } & \multicolumn{2}{|c|}{ Capsule } & \multicolumn{2}{|c|}{ Tea-bag } \\
\hline & & & EI & $\mathrm{CI}$ & EI & $\mathrm{CI}$ & EI & $\mathrm{CI}$ \\
\hline \multirow{2}{*}{ FEN } & \multirow{2}{*}{20} & 1 & $85.0 \pm 2.1$ & $80.3 \pm 6.2$ & $90.8 \pm 4.2$ & $82.8 \pm 8.9$ & $95.1 \pm 4.1$ & $90.3 \pm 5.2$ \\
\hline & & 100 & $99.1 \pm 2.9$ & $99.0 \pm 1.6$ & $97.6 \pm 2.8$ & $98.9 \pm 1.3$ & $97.1 \pm 1.8$ & $96.8 \pm 1.5$ \\
\hline \multirow{2}{*}{ NFE } & \multirow{2}{*}{$*$} & 1 & $100.8 \pm 2.9$ & $87.6 \pm 8.4$ & $95.9 \pm 6.4$ & $99.9 \pm 7.1$ & $96.7 \pm 3.0$ & $89.0 \pm 5.1$ \\
\hline & & 100 & $98.0 \pm 2.6$ & $92.8 \pm 2.6$ & $99.7 \pm 4.0$ & $101.7 \pm 3.4$ & $99.9 \pm 3.7$ & $95.9 \pm 4.9$ \\
\hline \multirow{2}{*}{ SIB } & \multirow[b]{2}{*}{10} & 1 & $101.0 \pm 3.1$ & $94.9 \pm 8.1$ & $98.9 \pm 3.8$ & $94.8 \pm 6.2$ & $96.5 \pm 1.6$ & $93.3 \pm 7.6$ \\
\hline & & 100 & $94.9 \pm 3.6$ & $97.2 \pm 3.6$ & $97.3 \pm 2.9$ & $95.0 \pm 3.7$ & $100.3 \pm 2.3$ & $96.0 \pm 3.3$ \\
\hline \multirow{2}{*}{ MAZ } & \multirow{2}{*}{1} & 1 & $93.7 \pm 4.3$ & $86.7 \pm 7.1$ & $99.7 \pm 2.6$ & $85.2 \pm 3.9$ & $100.5 \pm 3.3$ & $91.6 \pm 4.2$ \\
\hline & & 100 & $98.0 \pm 3.0$ & $98.2 \pm 5.2$ & $98.6 \pm 3.5$ & $95.4 \pm 2.6$ & $100.5 \pm 1.4$ & $95.4 \pm 3.0$ \\
\hline \multirow{2}{*}{ PHP } & \multirow{2}{*}{60} & 4 & $110.7 \pm 3.8$ & $93.0 \pm 7.7$ & $102.3 \pm 3.1$ & $102.2 \pm 8.6$ & $100.9 \pm 5.2$ & $82.9 \pm 1.9$ \\
\hline & & 200 & $101.7 \pm 2.6$ & $98.2 \pm 2.2$ & $101.7 \pm 2.5$ & $97.6 \pm 1.7$ & $102.9 \pm 0.8$ & $103.2 \pm 2.6$ \\
\hline
\end{tabular}

Data are represented the means \pm S.D. $(n=5)$.

* FEN derivative

Table 4. Analytical results of drugs in slimming health foods

\begin{tabular}{|c|c|c|c|c|c|c|c|c|}
\hline \multirow{2}{*}{$\begin{array}{c}\text { No. of } \\
\text { sample }\end{array}$} & \multirow{2}{*}{ Type } & \multirow{2}{*}{$\begin{array}{l}\text { Weight } \\
\text { (mg/unit) }\end{array}$} & \multirow{2}{*}{ Mode } & \multicolumn{5}{|c|}{ Concentration (mg/unit) } \\
\hline & & & & FEN & $\mathrm{NFE}$ & SIB & MAZ & PHP \\
\hline \multirow{2}{*}{1} & \multirow{2}{*}{ Tea-bag } & \multirow{2}{*}{$2,912.0$} & EI & 8.7 & ND & ND & ND & ND \\
\hline & & & $\mathrm{CI}$ & 8.5 & ND & ND & ND & ND \\
\hline \multirow{2}{*}{2} & \multirow{2}{*}{ Capsule } & \multirow{2}{*}{220.0} & EI & ND & 4.5 & ND & ND & ND \\
\hline & & & CI & ND & 5.2 & ND & ND & ND \\
\hline \multirow{2}{*}{3} & \multirow{2}{*}{ Capsule } & \multirow{2}{*}{396.2} & EI & $\mathrm{ND}$ & ND & 6.3 & 1.0 & 124.1 \\
\hline & & & $\mathrm{CI}$ & ND & ND & 6.3 & 1.0 & 124.5 \\
\hline \multirow{2}{*}{4} & \multirow{2}{*}{ Capsule } & \multirow{2}{*}{216.5} & EI & ND & ND & 8.4 & ND & 15.8 \\
\hline & & & $\mathrm{CI}$ & ND & ND & 8.2 & ND & 16.2 \\
\hline
\end{tabular}

ND: $<$ LOD, see Table 2. 

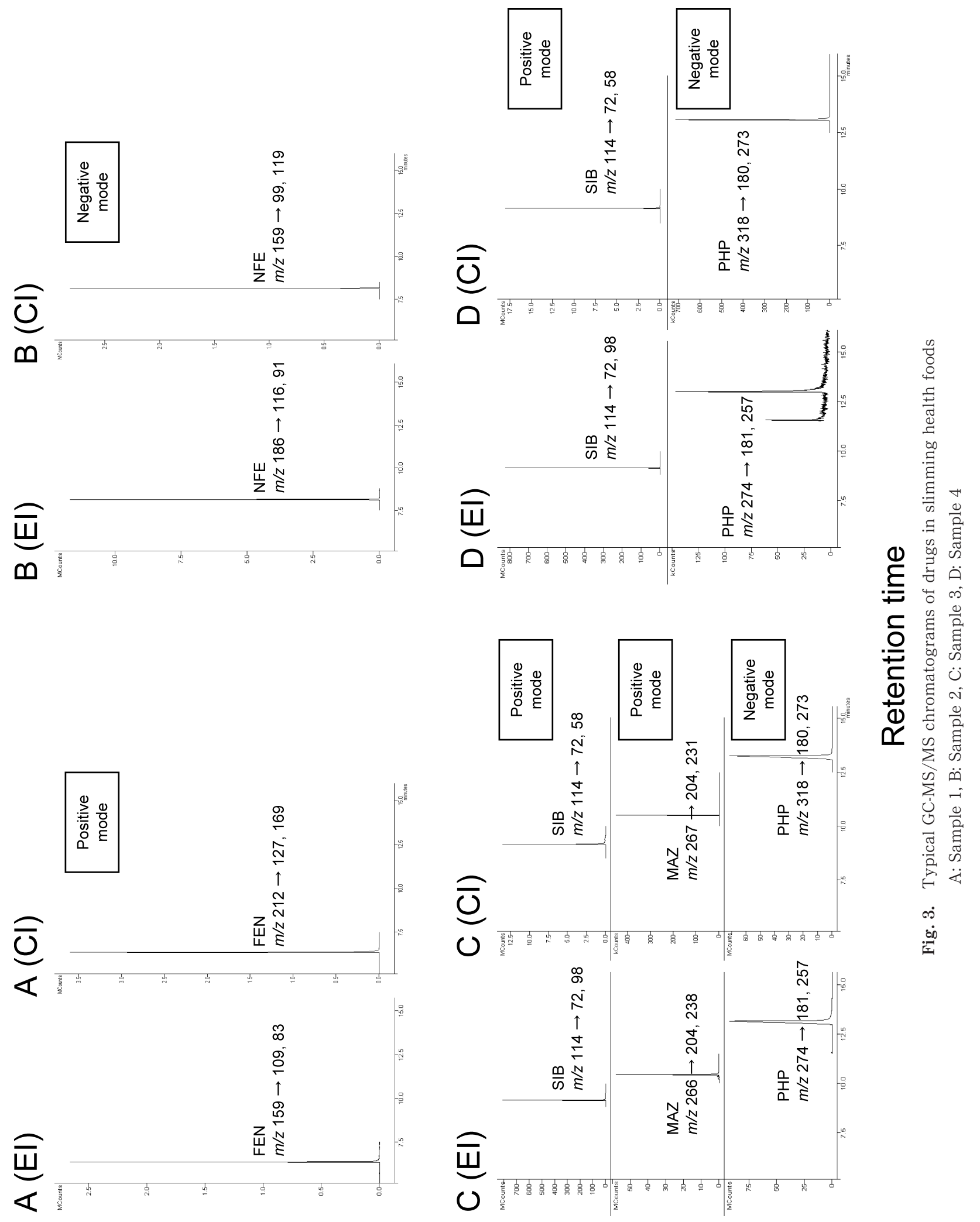

Kı!suəłu| 
製ダイエット茶葉中の FEN の確認を行っている. 本研究 では，高感度かつ高い選択性を有した Multiple Reaction Monitoring (MRM) 法でEI およびCI 法それぞれの測定 条件を作成した (Table 1). 各成分の標準溶液を装置に注 入し，フルスキャンにて高分子側で強度の強いイオンを選 択し，プリカーサーイオンとした後，特徵的な 2 種のプ ロダクトイオンを選択し，感度の高いものを定量イオン， 他方を確認イオンとした。 そして, 各成分のプロダクトイ オンを最も効率的に生成させるコリジョンエネルギーを検 討した。なお CI 法では, FEN, SIB, MAZ がポジティブ, NFE, PHP がネガティブモードによって取り込むことで 高い感度が得られた。本条件により分析した標準溶液の代 表的なクロマトグラムを Fig. 2 に示す。これより，EI お よび CI 法ともに 13.5 分以内にすべての成分を検出するこ とができた。

\section{2. 検量線および検出限界}

作成した条件を用いて 5 成分を同時検出したときに， クロマトグラム上で 5 つのピークを同時に観察しやすい 濃度範囲で検量線を作成したところ，EI および CI 両法に おいて FEN, NFE, MAZ はそれぞれ 0.5〜 $5 \mu \mathrm{g} / \mathrm{mL}, \mathrm{SIB}$ は 0.25〜2.5 $\mu \mathrm{g} / \mathrm{mL}, \mathrm{PHP}$ は $12.5 \sim 100 \mu \mathrm{g} / \mathrm{mL}$ の濃度範 囲で相関係数 0.999 以上の良好な直線性を示した。また， $S / N$ 比が 3 となる值をクロマトグラム上から検出限界と して算出し, 試料中濃度に換算した值を Table 2 に示す.

\section{3. 添加回収実験}

添加回収実験の結果を Table 3 に示す。対象成分を含 有していないことをあらかじめ確認した錠型, カプセル 型, ティーバッグ型の各 1 試料を粉砕後 $50 \mathrm{mg}$ 秤取し た。各医薬品成分の初期薬用量を参考に 2 濃度の添加用 標準溶液を調製, 添加した後 Scheme 1 に従って試験溶 液を作製した。なお，PHPは1998年に医薬品としての 製造が中止されているため, 過去の薬用量を参考とし た ${ }^{1)}$. $1 \mu \mathrm{g} / \mathrm{mg}$ (PHPについては $4 \mu \mathrm{g} / \mathrm{mg}$ ) を添加した 場合，EI 法で 85.0〜 110.7\%，CI 法で 80.3〜 102.2\%の 回収率が得られた。一方，100 $\mathrm{g} / \mathrm{mg}$ (PHPについては $200 \mu \mathrm{g} / \mathrm{mg}$ ）を添加した場合， EI 法で 94.9〜 102.9\%, CI 法で 92.8〜 103.2\%の回収率が得られた. 以上の結果 は，5成分がわずかに添加された濃度から効果を発揮する 量を添加した濃度まで分析できる方法であることを示唆す るあのである，また本法は，高速液体クロマトグラフィー で健康食品分析を行った際に疑わしい成分が検出された場 合でも有効な確認手段になりえると考える。

\section{4. 市販品への応用}

本法を用いて市販健康食品 14 検体の分析を行った。過 去に医薬品成分が検出された検体 1 (ティーバッグ型) か ら FEN として $8.7 \mathrm{mg} /$ unit (EI 法), $8.5 \mathrm{mg} /$ unit (CI 法), 検体 2 (カプセル型) から NFEとして $4.5 \mathrm{mg} /$ unit (EI 法), $5.2 \mathrm{mg} /$ unit (CI 法), 検体 3 (カプセル型) か ら SIB として $6.3 \mathrm{mg} /$ unit (EI 法), $6.3 \mathrm{mg} /$ unit (CI 法), MAZとして $1.0 \mathrm{mg} /$ unit (EI 法), $1.0 \mathrm{mg} /$ unit
(CI 法), PHP として $124.1 \mathrm{mg} / \mathrm{unit}$ (EI 法), $124.5 \mathrm{mg} /$ unit（CI 法)，検体 4（カプセル型）から SIB として 8.4 $\mathrm{mg}$ /unit (EI 法), $8.2 \mathrm{mg} /$ unit (CI 法), PHP として $15.8 \mathrm{mg} /$ unit (EI 法), $16.2 \mathrm{mg} /$ unit (CI 法) を検出し, EI および CI 両法の定量值は互いに近似するすのであっ た. 以上 4 検体の結果を Table 4 に，その際のクロマト グラムをFig. 3 に示す。一方, 平成 20 年 11 月に購入し た 10 検体中に対象医薬品成分が検出されたものはなかっ た。

\section{ま と め}

ダイエット効果を標榜した健康食品中の医薬品 5 成分 について GC-MS/MS による一斉分析法を検討した。各成 分について適切なプロダクトイオンとコリジョンエネル ギーを設定することができた。そして，EI と CI の 2 種の イオン化法を用いて分析を行ったところ，各法ともに良好 な回収率と定量結果を得ることができた。また，定量まで の一連の操作は 1 検体当たり約 80 分で完結し，迅速性を 求められる健康危機管理対策上の行政検査に対しても本法 は十分な有効性を示すむのと考えられる.

\section{文献}

1) 内藤裕史. “第 $\mathrm{I}$ 部 瘦せ薬”。健康食品中毒百科. 東京, 丸善, 2007, p. 3-71. (ISBN 978-4-621-07840-2)

2) Flurer, C. L., Lin, L. A., Satzger, R. D., Wolnik, K. A. Determination of ephedrine compounds in nutritional supplements by cyclodextrin-modified capillary electrophoresis. J. Chromatogr. B, 669, 133-139 (1995).

3) Takagi, T., Kimoto, S., Makino, Y., Nasu, M. Components of herbal ecstacies. Eisei Kagaku (Jpn. J. Toxicol. Environ. Health), 43, 197-201 (1997).

4) Seto, T., Shioda, H., Satoh, K., Hamano, T., Onishi, K. Detection of senna and rhubarb used only as drugs from herbal teas advertising effect of weight reduction. Eisei Kagaku (Jpn. J. Toxicol. Environ. Health), 44, 195-203 (1998).

5) Yasuda, I. The medical supplies resemblance ingredient in health foods. Shokuhin Eiseigaku Zasshi (Food Hyg. Saf. Sci.), 51, 402-407 (2010).

6) Nelson, L., Shih, R., Hoffman, R. Aplastic anemia induced by an adulterated herbal medication. Clin. Toxicol., 33, 467-470 (1995).

7) Kojima, T., Kishi, M., Sekita, S., Satake, M. Origin of sennosides in dietary supplements containing senna stem. Shokuhin Eiseigaku Zasshi (J. Food Hyg. Soc. Japan), 41, 303-306 (2000).

8) 熊谷浩樹. “機器分析一その測定之実際- 18 . 液体クロマ トグラフィー/質量分析法”。分析化学実験の単位操作法. 社団法人日本分析化学会編, 東京, 朝倉書店, 2004, p. 182-186. (ISBN 4-254-14063-0)

9) Takeda, K., Ishiguro, Y., Tanaka, R., Maruyama, J., Kasamatsu, T., Okawa, S., Hori, S. Study on the determination of pesticide residues in crops by ion-trap GC/MS/MS. Shokuhin Eiseigaku Zasshi (J. Food Hyg. 
Soc. Japan), 43, 280-288 (2002).

10) Inoue, T., Sasaki, S., Uchikawa, S., Hirahara, Y., Shiomi, Y., Tonogai, Y. Determination of low-level pesticides residues in agricultural products by ion-trap GC/MS/MS. Shokuhin Eiseigaku Zasshi (J. Food Hyg. Soc. Japan), 44, 310-315 (2003).

11）三上栄一, 大野 勉, 岡 尚男, 石原廣男. 個人輸入した ダイエット食品に検出された医薬品成分に関する検討，医
療薬学, 31(1), 52-57 (2005).

12) 三上栄一, 池田清栄, 大野 勉. ダイエット用健康食品 (美秀堂, 加強型) に添加された医薬品成分の検索. 愛知 県衛生研究所年報, 58, 29-35 (2008).

13) 三上栄一, 後藤智美, 大野 勉, 早川順子, 加賀美忠明. 中国産減肥茶に添加された食欲抑制剤（フェンフルラミ ン）の分析. 愛知県衛生研究所年報, 48, 9-13 (1998). 